\title{
Discriminant analysis of morphometric differentiation in the West African Dwarf and Red Sokoto goats
}

\author{
A. Yakubu ${ }^{1,2 \#}$, A.E. Salako ${ }^{2}$, I.G. Imumorin ${ }^{3}$, A.O. Ige ${ }^{4}$ and M.O. Akinyemi ${ }^{2}$ \\ ${ }^{1}$ Department of Animal Science, Faculty of Agriculture, Nasarawa State University, Keffi, Shabu-Lafia \\ Campus, P.M.B. 135, Lafia, Nigeria \\ ${ }^{2}$ Animal Breeding and Genetics Laboratory, Department of Animal Science, University of Ibadan, Ibadan, Nigeria \\ ${ }^{3}$ Department of Animal Science, B267 Morrison Hall, Cornell University, Ithaca, NY. 14853. USA \\ ${ }^{4}$ Department of Animal Production and Health, Ladoke Akintola University of Technology, Ogbomoso, Nigeria
}

\begin{abstract}
This study evaluated the usefulness of morphological characteristics to distinguish two important indigenous goat breeds in Nigeria. Fifteen morphometric traits were measured on West African Dwarf WAD ( $n=160)$ and Red Sokoto - RS $(n=142)$ goats that ranged in age of up to 19 months and were reared extensively in villages in southern and northern Nigeria. Univariate analysis revealed that the body measures of RS goats were significantly higher than those of WAD goats. Canonical discriminant analysis gave better resolution, as only seven external morphological characteristics of strong discriminating power were extracted. The most discriminant variable between the two goat populations was rump height, followed in order by body length, horn length, face length, chest girth, neck circumference and head width. The discriminant function obtained correctly classified $100 \%$ of individuals from the sample of known goat populations. The classification accuracy of the function was cross-validated using the split-sample method, and indicated a $99.7 \%$ success rate $(99.4 \%$ of WAD goats and $100 \%$ of RS goats were correctly assigned to their source genetic group). This study indicates that a discriminant tool may be used successfully in the field to separate WAD and RS goats. The present results could be complemented by molecular characterization using DNA markers for better management and conservation strategies of genetic resources for indigenous goats.
\end{abstract}

Keywords: Indigenous goats, morphological traits, multivariate

\# Corresponding author. Email: abdul_mojeedy@yahoo.com

\section{Introduction}

In Nigeria goats represent a veritable resource for economic development and livelihood security in addition to major cultural importance. The population of goats in the country is estimated at 34.5 million (RIM, 1992) of which traditionally reared stock contributes $99.97 \%$, while $0.03 \%$ of the stock is commercially managed. However, the projected population for 2010 is 46,568,000 (Shaib et al., 1997). Red Sokoto (RS) and West African Dwarf (WAD) goats are the two most important goat breeds found in the country. They are kept as a source of food and investment. Their ability to tolerate harsh climates, remarkable recovery capacity from drought, suitability to traditional systems due to small size, short generation interval (Odubote, 1994) and ability to thrive on poor quality diets resulting from scarce grazing on marginal land (Hoste et al., 1988) make goats strategic in increasing livestock productivity in rural agricultural systems (Fitzugh et al., 1992). While RS are more adaptable to the climatic conditions of northern Nigeria, WAD are trypanotolerant (Hoste et al., 1988) and able to inhabit the trypano-endemic humid zones of southern Nigeria. Both breeds are meat breeds, although the skin of RS goats is reputed to be of high quality and used in the leather industry locally and internationally (Akpa et al., 1998).

Extensive genetic diversity in animal breeds allows for the existence of livestock in all but the most extreme environment globally, providing a range of products and functions (Rege \& Gibson, 2003). Unfortunately, a large number of breeds has been lost and many more are at the risk of extinction. Therefore, genetic erosion in animal genetic resources (AnGR) is of concern where livelihoods of the poor are affected (Anderson \& Centoze, 2007). An important research and development goal is the systematic evaluation of breeds in production systems where they are typically found, quantitative assessment of the genetic diversity they possess, the definition of relationships among breeds and the implementation of programmes for their 
effective management, including development of policies and strategies for conservation and sustainable utilization. Conservation and sustainable development of animal genetic resources require a broad focus that includes the many adaptive breeds that survive well in the low external input agriculture typical of developing countries (Drucker et al., 2001).

According to the FAO, a global strategy involves identifying and understanding the unique genetic resource in a particular region and to develop the use of the associated diversity (Franklin, 1997). Appropriate design of breeding programmes is impossible for breeds that have not been adequately characterized either phenotypically and/or genetically (Mwacharo et al., 2006). Phenotypic characteristics are important in breed identification and classification. The first step of the characterisation of local genetic resources is to assess variation of morphological traits (Delgado et al., 2001). In Nigeria, morphometric differentiation of indigenous small ruminant populations has been restricted to the use of analysis of variance (Fajemilehin \& Salako, 2008). However, such type of analysis has limited power and multifactorial analyses of morphological traits are more appropriate to assess phenotypic variation within and between goat populations; and to appropriately discriminate different goat types because of the joint consideration of all measured morphological variables (Lanari et al., 2003; Zaitoun et al., 2005; Dossa et al., 2007; Traore et al., 2008). This becomes imperative because uncontrolled mating and geographical overlap are leading to the endangerment of breed purity and potentially important reservoir of caprine genetic resources is being put at risk.

The aim of this study was to evaluate morphological characteristics of WAD and RS goats using canonical discriminant analysis. This approach represents a better scientific basis for effective classification, management and sustainable exploitation of the genetic resources of the two goat populations, and avoiding fraud since conformation plays a major role in selling breeding stock (Fuerst-Waltl \& Baumung, 2006).

\section{Materials and Methods}

The experiment made use of a random sample of 160 WAD goats of both sexes (113 females and 47 males) and 142 RS goats (98 males and 44 females). While the WAD goats were selected in certain villages located in Oyo State, south-western Nigeria, the RS goats were sampled in villages around Sokoto, Kaduna and Kano States in the northern part of the country. The animals ranged in age of up to 19 months, using dentition (animals having 2 - 8 permanent incisors) as described by Matika et al. (1992). The relatively high number of females could be attributed to the fact that they are normally retained in the breeding flock by farmers for reproduction while the males are more frequently put up for sale. Sampling was restricted to the regions of origin of the two goat breeds to guarantee the measurements of purebreds only.

The animals were extensively managed with little or no provision for shelter in the night. The animals grazed during the day on natural pasture containing forages such as northern gamba grass (Andropogon gayanus), stylo (Stylosanthes gracilis), leucaena (Leucaena leucocephala) and guinea grass (Panicum maximum), and scavenged on kitchen wastes when available.

Fifteen morpho-biometrical characteristics were taken on each animal in the morning before they were released for grazing. Measurements were restricted to apparently healthy goats that conformed to the classification descriptors of each breed. The body parts measured were as described by Adebayo (2009) and Yakubu (2009). They included rump height (RH), measured vertically from the ground to the top of the pelvic girdle; body length (BL), measured diagonally from the lateral tuberosity on the scapula to the pinbone; face length (FL), distance from between the horn site to the lower lip; ear length (EL), distance from the point of attachment to the tip of the ear; horn length (HL), measured from the temple of the head to the tip of the horn; rump length (RL), measured as the distance from the hip (tuber coxa) to the pin (tuber ischi); tail length (TL), measured from the base of the tail to the end of the coccygeal vertebrae; neck circumference (NC), taken as the distance round the mid region of the neck; abdominal circumference (AC), measured as body circumference in front of the sacrum; cannon circumference (CC), recorded as the smallest circumference of the foreleg; chest girth (CG), measured as the body circumference just behind the forelegs; chest depth (CD), the dorsal-ventral distance between the most dorsal point of the withers and the ventral surface of the sternum; head width (HW), measured between the roots of the horns and the nuchal crest; shoulder width (SW), measured as the distance between the processes on the left shoulder blade and that on the right shoulder blade, and rump width (RW), distance between the two tuber coxae.

The height measurement $(\mathrm{cm})$ was performed using a graduated measuring stick. The length and circumference measurements $(\mathrm{cm})$ were measured with a tape rule while the width measurements were taken 
using a calibrated wooden calliper. All measurements were carried out by the same person in order to avoid between-individual variations.

Means ( \pm s.e.), standard deviations and coefficients of variation of the morphometric characteristics of WAD and RS goats adjusted for age and sex effects were computed. Canonical discriminant analysis, a multivariate technique was used to identify the combination of variables that best separate the two genetic groups. This analysis is a multivariate technique that describes the relationship between two variable sets by calculating the linear combinations that are maximally correlated (Tabachnick \& Fidel, 2001). The ultimate goal of a discriminant function analysis is to evaluate the relative contribution of each independent variable to the derived canonical functions in order to explain the nature of the relationship(s). In the present study, the 15 morphometric variables were stepwise introduced as predictor variables into the discriminant analysis. The relative importance of the morphometric variables in discriminating the two goat populations was assessed using the F-to-remove statistic. Collinearity among the variables used in the discriminant model was evaluated using tolerance statistic. For breed identification, the unstandardized discriminant function procedure of the canonical discriminant analysis was employed (this function has the form of a multiple regression equation). The ability of this function to identify West African Dwarf and Red Sokoto goats was indicated as the percentage of individuals correctly classified from the sample that generated the function. Accuracy of the classification was evaluated using split-sample validation (cross-validation). In crossvalidation, one individual is removed from the original matrix and the discriminant analysis is then performed from the remaining observations and used to classify the omitted individual. The proportion of individuals correctly re-allocated is taken as a measure of the morphological distinctness of the population. All analyses were done using a SPSS (2001) statistical package.

Table 1 Descriptive statistics of the morphometric traits of West African Dwarf and Red Sokoto goats

\begin{tabular}{|c|c|c|c|c|c|c|}
\hline \multirow{2}{*}{ Trait } & \multicolumn{2}{|c|}{ West African Dwarf goat } & \multirow[b]{2}{*}{$\mathrm{CV}$} & \multicolumn{2}{|c|}{ Red Sokoto goat } & \multirow[b]{2}{*}{$\mathrm{CV}$} \\
\hline & Mean \pm s.e. & $\mathrm{SD}$ & & Mean \pm s.e. & SD & \\
\hline Rump height & $45.96^{\mathrm{b}} \pm 0.32$ & 4.03 & 8.77 & $66.53^{\mathrm{a}} \pm 0.51$ & 6.06 & 9.10 \\
\hline Body length & $45.10^{\mathrm{b}} \pm 0.38$ & 4.74 & 10.51 & $51.63^{\mathrm{a}} \pm 0.41$ & 4.84 & 9.37 \\
\hline Face length & $15.02^{\mathrm{b}} \pm 0.26$ & 3.27 & 21.77 & $21.94^{\mathrm{a}} \pm 0.15$ & 1.79 & 8.15 \\
\hline Ear length & $10.85^{\mathrm{b}} \pm 0.13$ & 1.69 & 15.58 & $14.52^{\mathrm{a}} \pm 0.15$ & 1.79 & 12.33 \\
\hline Horn length & $7.03^{\mathrm{b}} \pm 0.15$ & 1.86 & 26.46 & $13.07^{\mathrm{a}} \pm 0.17$ & 2.02 & 15.46 \\
\hline Rump length & $11.44^{\mathrm{b}} \pm 0.11$ & 1.44 & 12.58 & $14.51^{\mathrm{a}} \pm 0.16$ & 1.89 & 13.03 \\
\hline Tail length & $11.22^{\mathrm{b}} \pm 0.09$ & 1.16 & 10.34 & $13.52^{\mathrm{a}} \pm 0.14$ & 1.70 & 12.57 \\
\hline Neck circumference & $21.96^{\mathrm{b}} \pm 0.18$ & 2.27 & 10.34 & $30.61^{\mathrm{a}} \pm 0.25$ & 2.93 & 9.57 \\
\hline Abdominal circumference & $71.37^{\mathrm{b}} \pm 0.59$ & 7.49 & 10.49 & $80.41^{\mathrm{a}} \pm 0.54$ & 6.43 & 8.00 \\
\hline Cannon circumference & $6.97^{\mathrm{b}} \pm 0.08$ & 0.96 & 13.77 & $9.83^{\mathrm{a}} \pm 0.08$ & 1.01 & 10.27 \\
\hline Chest circumference & $60.09^{\mathrm{b}} \pm 0.49$ & 6.20 & 10.32 & $69.81^{\mathrm{a}} \pm 0.56$ & 6.65 & 9.53 \\
\hline Chest depth & $26.43^{\mathrm{b}} \pm 0.31$ & 3.87 & 14.64 & $31.42^{\mathrm{a}} \pm 0.31$ & 3.66 & 11.65 \\
\hline Head width & $9.41^{b} \pm 0.12$ & 1.49 & 15.83 & $12.13^{\mathrm{a}} \pm 0.16$ & 1.91 & 15.75 \\
\hline Shoulder width & $10.81^{\mathrm{b}} \pm 0.15$ & 1.88 & 17.39 & $14.24^{\mathrm{a}} \pm 0.15$ & 1.74 & 12.22 \\
\hline Rump width & $9.69^{\mathrm{b}} \pm 0.12$ & 1.54 & 15.89 & $12.84^{\mathrm{a}} \pm 0.16$ & 1.92 & 14.95 \\
\hline
\end{tabular}

s.e.- Standard error; SD- Standard deviation; CV- Coefficient of variation.

${ }^{\mathrm{a}, \mathrm{b}}$ Means in the same row with different superscripts are significantly different at $\mathrm{P}<0.05$.

\section{Results}

Univariate analysis of variance (ANOVA) revealed significant $(\mathrm{P}<0.05)$ differences in all the morphometric measurements, with higher means recorded for the RS goats compared to their WAD 
counterparts (Table 1). Apart from horn length which was more variable in both breeds, the coefficients of variation for other linear type traits did not follow a definite pattern.

Results of the stepwise discriminant analysis showing Wilk's Lambda values, F-values, probability and tolerance statistics are presented in Table 2. The discriminant analysis based on significant F-values indicated rump height, body length, horn length, face length, chest girth, neck circumference and head width as the linear measures permitting discrimination between the WAD and RS goats. When the seven most important morphometric traits for separating the two goat breeds were selected, Wilk's Lambda dropped to 0.078 with a significant difference between the two goat breeds $(\mathrm{F}=13.162 ; \mathrm{P}<0.001)$. The unstandardized stepwise discriminant function was used to classify individual goats. The seven discriminating variables earlier extracted were the variables included in the discriminant (D) equation:

$$
\mathrm{D}=-6.786+0.300 \mathrm{RH}-0.185 \mathrm{BL}+0.172 \mathrm{FL}+0.273 \mathrm{HL}-0.112 \mathrm{HG}-0.199 \mathrm{HW}+0.098 \mathrm{NC} \text {. }
$$

Table 2 Morphological characters selected by stepwise discriminant analysis to separate West African Dwarf and Red Sokoto goats

\begin{tabular}{lcccc}
\hline Variable & Wilk's Lambda & F-remove & P-Level & Tolerance \\
\hline Rump height & 0.180 & 412.064 & 0.0001 & 0.271 \\
Body length & 0.091 & 63.385 & 0.0001 & 0.245 \\
Horn length & 0.091 & 60.691 & 0.0001 & 0.664 \\
Face length & 0.087 & 45.019 & 0.0001 & 0.682 \\
Chest girth & 0.085 & 38.370 & 0.0001 & 0.240 \\
Neck circumference & 0.080 & 19.105 & 0.0001 & 0.660 \\
Head width & 0.078 & 13.162 & 0.0001 & 0.404 \\
\hline
\end{tabular}

Table 3 Classification results for the discriminant analysis of goat populations

\begin{tabular}{lcccc}
\hline & Species & \multicolumn{2}{c}{ Predicted Group Membership } & Total \\
\cline { 3 - 4 } & & 1.00 & 2.00 & 160 \\
Original count & 1.00 & 160 & 0 & 142 \\
$\%$ & 2.00 & 100.0 & 0.0 & 100.0 \\
& 1.00 & 0.0 & 100.0 & 100.0 \\
Cross-validated & 2.00 & 159 & 1 & 160 \\
count & & 0 & 142 & 142 \\
\% & 1.00 & 99.4 & 0.6 & 100.0 \\
& 2.00 & 0.0 & 100.0 & 100.0 \\
\hline
\end{tabular}

Species $1.00=$ West African Dwarf goats; $2.00=$ Red Sokoto goats. $100 \%$ of the original grouped cases correctly classified. $99.7 \%$ of cross-validated grouped cases correctly classified.

The discriminant function was able to correctly classify 100\% of the 160 WAD and 142 RS goats investigated (Table 3). Cross-validation with the split-sample method indicated a 99.7\% average success rate (99.4\% of WAD and 100\% of RS goats were correctly assigned into their distinct genetic groups).

\section{Discussion}

Phenotypes are an expression of genetic characteristics, modified by environmental condition; and variance in both genetics and environment may affect phenotypic variance. The characterization of African 
native animal genetic resources is currently receiving increased attention (Dossa et al., 2007; Traore et al., 2008; Yakubu et al., 2009). Mammalian body measurements are used to make taxonomic, behavioural and ecological comparisons within and among species. Another application of these comparisons is the promulgation of several rules to explain intraspecific variation in morphology over broad environmental gradients (Brown et al., 2006). The pattern of morphometric distinctness detected between WAD and RS goats suggests a direct relationship between the extent of morphometric divergence and geographical separation. This could have resulted from phenotypic plasticity, an environmental-induced phenotypic change that occurs within an organism's lifetime, and which is an important adaptive strategy to help cope with environmental variability (WAD are more suited to the humid tropical environment of southern Nigeria while RS goats predominate in the Savannah parts of northern Nigeria). This is in accordance with the results of Brown et al. (2006) that temporal and spatial variation in weather, plant productivity and subsequent nutrition could have major impacts on physical growth of animals. The estimates obtained for chest depth and ear length in WAD goats in this study were consistent with those reported for coastal goat population of Benin (24.3 chest depth and 9.45 ear length, respectively), although the latter was on the average longer in body length $(69.7 \mathrm{~cm})$ (Dossa et al., 2007). While the RS goats of Nigeria compared well with Sahelian goats of Burkina Faso, they were higher in body measure values than the Sudan and Sudan-Sahel goats of the latter (Traore et al., 2008). The varying coefficients of variation in this study could be attributed to breed differences, influence of the environment on the parameters, especially the width measurements, and absence of directed selection.

Although the univariate statistics showed RS goats to be significantly higher in all measurements, the multivariate technique provided better resolution. Stepwise procedure allowed the selection of the most discriminating variables that enable a clear separation between the two genotypes. The tolerance values obtained in the present study were greater than 0.1. This is an indication that there was no collinearity problem (Gill, 1986; Yakubu, 2009) among the seven most discriminating morphometric variables. All resultant morphometric characteristics of major discriminant loads, except chest girth of this study are environmentally independent and thus indicate inherent size. Some of the present discriminant variables are similar to those found by Herrera et al. (1996) working on Andalusian breeds and Crepaldi et al. (2001), working on goat populations from the Lombardy Alps. In a related study in sheep, Salako \& Ngere (2002) reported that head width, face length (cephalic characters), body length and withers height were among the six variables used to place WAD and Yankasa sheep in a determined population, thereby reducing assignment error levels.

The classification function obtained in this study could directly be used to identify the two breeds, since positive D scores indicate RS goats and negative D scores indicate WAD goats. The seven discriminating variables extracted were sufficiently robust to be used in the field to separate the two goat populations. The use of biometrics therefore may considerably increase the reliability of the classification of different goat breeds. In a related investigation, Dossa et al. (2007) was able to correctly allocate more than $70 \%$ of individual goats into their different groups. Similarly, Traore et al. (2008) used discriminant analysis to correctly classify most Sudan and Sudan-Sahel goat populations of Burkina Faso into their source population (79.3\% and $82.7 \%$, respectively). The present classification function is the first tool available to differentiate between WAD and RS goats under field conditions, which could aid their effective management and conservation. This is important because the potential capacity of populations to adapt and evolve as independent biological entities in different environmental conditions is restricted by the exchange of individuals between populations. The function provides important and informative variables (racial markers) that could be used to assign the two goat breeds into distinct populations, thereby reducing the errors of selection in future breeding programmes. The increasing activities of Fulani pastoralists lead to indiscriminate flock movement, traditional livestock exchange and transportation of livestock by traders from one part of the country to another, which could lead to genetic erosion. Classification purely on colour basis might not be reliable as the varying coat colour of WAD goats, include the red and brown colours that RS goats are known for. According to Gertenbach \& Kars (1999), conservation seems more appropriate in the context of gene pool maintenance by keeping animal genetic resources from harm. The discriminating variables obtained in this study might not be exhaustive as the inclusion of other conventional and nonconventional variables might produce more discriminants. More evidence drawn from biochemical and molecular genetics will also consolidate information arising from morphological variability. In a related study in sheep, Kunene et al. (2007) reported that information derived from linear body measurements could 
be used to support genetic analyses to determine variation between and within small populations to develop effective conservation and utilization programmes.

\section{Conclusions}

This study showed that rump height, body length, horn length, face length, chest girth, neck circumference and head width were the most discriminating variables to separate WAD and RS goats. The present findings could aid field assessment, management and conservation of the two goat populations, where the goal is to obtain phenotypically pure local genetic resources for sale and/or for future selection and breeding improvement strategies. However, an investigation on the genetic characterization of Nigerian goats using microsatellite markers will complement the results obtained from morphometric differentiation.

\section{References}

Adebayo, A.T., 2009. Application of principal component factor analysis in quantifying size and morphometric traits of West African Dwarf goats in Oyo State. Unpublished Postgraduate Diploma Thesis, Department of Animal Science, Nasarawa State University, Keffi, Shabu-Lafia Campus, Lafia, Nigeria. 39 pp.

Akpa, G.N., Duru, S. \& Amos, T.T., 1998. Influence of strain and sex on estimation of within age group body weight of Nigerian Maradi goats from their linear body measurements. Trop. Agric. (Trinidad) $75,462-467$.

Anderson, S. \& Centoze, R., 2007. Property rights and the management of animal genetic resources. Wrld Develop. 35, 1529-1541.

Brown, D.E., Maher, C.R. \& Mitchell, C.D., 2006. A comparison of Pronghorn body measurements throughout western North America. Proc. $22^{\text {nd }}$ Biennial Pronghorn Workshop, USA. pp. 125-137.

Crepaldi, P., Negrini, R., Milanesi, E., Gorni, C., Cicogna, M. \& Ajmone-Marsan, P., 2001. Diversity in five goat populations of Lombardy Alps: Comparison of estimates obtained from morphometric traits and molecular markers. J. Anim. Breed. Genet. 118, 173-189.

Delgado, J.V., Barba, C., Camacho, M.E., Sereno, F.T.P.S., Martinez, A. \& Vega-Pla, J.L., 2001. Livestock characterisation in Spain. AGRI. 29, 7-18.

Dossa, L.H., Wollny, C. \& Gauly, M., 2007. Spatial variation in goat populations from Benin as revealed by multivariate analysis of morphological traits. Small Rumin. Res.73, 150-159.

Drucker, A.G., Gomez, V. \& Anderson, S., 2001. The economic valuation of farm animal genetic resources: a survey of available methods. Ecol. Econ. 36, 1-18.

Fajemilehin, O.K.S. \& Salako, A.E., 2008. Body measurements characteristics of the West African Dwarf (WAD) goats in deciduous forest zone of southwestern Nigeria. Afr. J. Biotechnol. 7, 2521-2526.

Fitzugh, H.A., Ehui, S.K. \& Lahlou-Kassi, A., 1992. Research strategies for development of animal agriculture. Wrld Anim. Rev. 72, 9-19.

Franklin, I.R., 1997. The utilization of genetic variation. Proc. Assoc. Advmt. Anim. Breed. Genet. 12, 641-647.

Fuerst-Waltl, B. \& Baumung, R., 2006. Economic weights for conformation traits in Mountain sheep. Arch. Tierz. Dummerstorf 49, 575-582.

Gertenbach, W.D. \& Kars, A.A., 1999. Towards the conservation of the indigenous cattle of KwaZulu-Natal. S. Afr. J. Anim. Sci. 29, 55-63.

Gill, J.L., 1986. Outliers and influence in multiple regression. J. Anim. Breed. Genet. 103, 161-175.

Herrera, M., Rodero, E., Gutierrez, M.J., Pena, F. \& Rodero, J.M., 1996. Application of multifactorial discriminant analysis in the morphostructural differentiation of Andalusian caprine breeds. Small Rumin. Res. 22, 39-47.

Hoste, C.H., Chalon, E., D’leteren, G. \& Trail, J.C.M., 1988. Trypanotolerant livestock in west and central Africa. FAO Animal Health and Production Papers 20 (2), 56-67.

Kunene, N., Nesamvuni, E.A. \& Fossey, A., 2007. Characterization of Zulu (Nguni) sheep using linear body measurements and some environmental factors affecting these measurements. S. Afr. J. Anim. Sci. 37, 11-20.

Lanari, M.R., Taddeo, H., Domingo, E., Centeno, M.P. \& Gallo, L., 2003. Phenotypic differentiation of exterior traits in local Criollo goat population in Patagonia (Argentina). Arch. Tierz. Dummerstorf 46, 347-356. 
Matika, O., Sibanda, R. \& Beffa, M.L., 1992. Eruption of permanent incisors in indigenous goats and sheep. In: Small Ruminant Research and Development in Africa. Eds Rey, B., Lebbie, S.H.B. \& Reynolds, L., Proc. First Biennial Conference of the African Small Ruminant Research Network, ILRAD, Nairobi, Kenya, 10-14 December, 1990. pp. 499- 504.

Mwacharo, J.M., Okeyo, A.M., Kamande, G.K. \& Rege, J.E.O., 2006. The small East African shorthorn zebu cows in Kenya. 1: Linear body measurements. Trop. Anim. Health Prod. 38, 65-76.

Odubote, I.K., 1994. Genetic analysis of the reproductive performance of West African Dwarf goats in the humid tropics. In: Small Ruminant Research and Development in Africa. Eds Lebbie, S.H.B. \& Kagwini, E., Proc. Third Biennial Conference of African Small Ruminant Research Network, Kampala, Uganda. 5-9 December, 1994. pp. 33-36.

Rege, J.E.O. \& Gibson, J.P., 2003. Animal genetic resources and economic development: Issues in relation to economic valuation. Ecol. Econ. 45, 319-330.

RIM., 1992. Nigerian Livestock Resources: National Synthesis. Resource Inventory and Management Ltd., Jersey, UK.

Salako, A.E. \& Ngere, L.O., 2002. Application of multifactorial discriminant analysis in the morphometric structural differentiation of West African Dwarf (WAD) and Yankasa sheep in South West Nigeria. Nig. J. Anim. Prod. 29, 163-167.

Shaib, B., Aliyu, A. \& Balesh, J.S., 1997. Nigeria: National Agricultural Research Strategy Plan 1996-2010. Department of Agricultural Sciences, Ministry of Agriculture and Natural Resources. p. 271.

SPSS., 2001. Statistical Package for the Social Sciences. SPSS Inc., New York.

Tabachnick, B.G. \& Fidell, L.S., 2001. Using Multivariate Statistics. Allyn and Bacon, Boston, USA. pp. 966.

Traore, A., Tamboura, H.H., Kabore, A., Royo, L.J., Fernandez, I., Alvarez, I., Sangare, M., Bouchel, D., Poivey, J.P., Francois, D., Sawadogo, L. \& Goyache, F., 2008. Multivariate analyses on morphological traits of goats in Burkina Faso. Arch. Tierz. Dummerstorf 51, 588-600.

Yakubu, A., 2009. Fixing collinearity instability in the estimation of body weight from morpho-biometrical traits of West African Dwarf goats. Trakia J. Sci. 7, 61-66.

Yakubu, A., Ogah, D.M. \& Idahor, K.O., 2009. Principal component analysis of the morphostructural indices of White Fulani cattle. Trakia J. Sci. 7, 67-73.

Zaitoun, I.S., Tabbaa, M.J. \& Bdour, S., 2005. Differentiation of native goat breeds of Jordan on the basis of morphostructural characteristics. Small Rumin. Res. 56, 173-182. 